\title{
Advantages and recent advances of smart energy grid
}

\author{
Mohammed Qasim Taha \\ Department of Biophysics, College of Applied Sciences-Hit, University of Anbar, Iraq
}

\begin{tabular}{l} 
Article Info \\
\hline Article history: \\
Received Feb 9, 2020 \\
Revised Apr 3, 2020 \\
Accepted May 19, 2020 \\
\hline
\end{tabular}

\section{Keywords:}

Power system

Renewable energy

Smart energy systems

Smart grid

\begin{abstract}
Smart grid is widely recognized technology used to improve the stability and losses of the electric power system. It is encouraging reliability, efficiency, and effective control of the supply of electrical energy. However, it is a hot topic for recent publications and still has a limited understanding among researchers. This review work is to provide insight and support to the beginner researchers since this topic needs a multidisciplinary background knowledge. The conventional electric transmission system and distribution networks struggle to provide resilient performance and reliable service and real-time data. Also, smart grid id a promising network maneuver to stabilize the system once any disturbances break out by using the distributed renewable energy generators, while the conventional networks lack for flexibility to integrate with renewable energy generators or microgrids. This comprehensive work is conducted to map previous controbution in a coherent manar, including the specifications, features, and fundamentals that are presented to benefit the interested readers interested in smart grid development.
\end{abstract}

This is an open access article under the CC BY-SA license.

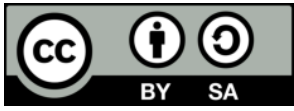

\section{Corresponding Author:}

Mohammed Qasim Taha,

Department of Biophysics,

University of Anbar, Ramadi, Iraq.

Email: as.mohammed_taha@uoanbar.edu.iq

\section{INTRODUCTION}

The smart energy system is mainly a new generation of smart power systems, it is a revolutionary technological form of electricity networking. It intelligently integrates the power system with communication technologies to control the distribution networks, transmission, and electricity generation. As a result, attractive, communicative and qualified system can cope the challenges of power networking [1-3]. It should be mentioned, the conventional power systems are originally planned and controlled by utilities to feed the costumers within the same country, and as evidenced in Figure 1.

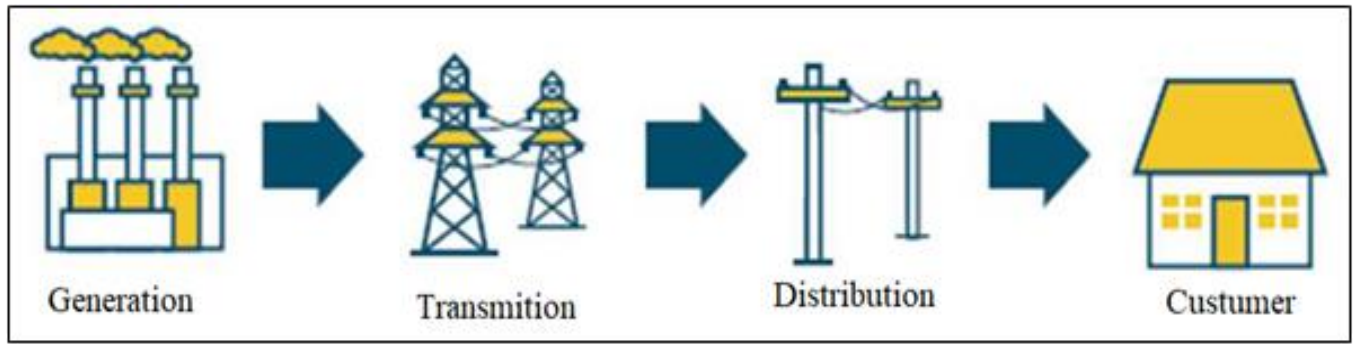

Figure 1. Traditional power flow in the conventional grid [4] 
A smart grid delivers a high efficiency, availability and flexibility. It is interdisciplinary integrated power grid depends on many elements such as digital sensing, smart metering, online monitoring, automation instruments to build a two-way communication-based power system allows the operation and consumer to interact each other to enhance service reliability compared with the existing power system. Nowadays, increasing two-directional power flows as exemplified in Figure 2, the grid is being augmented with many technologies to handle the evolving challenges such as energy storage, demand response, and generation [5].

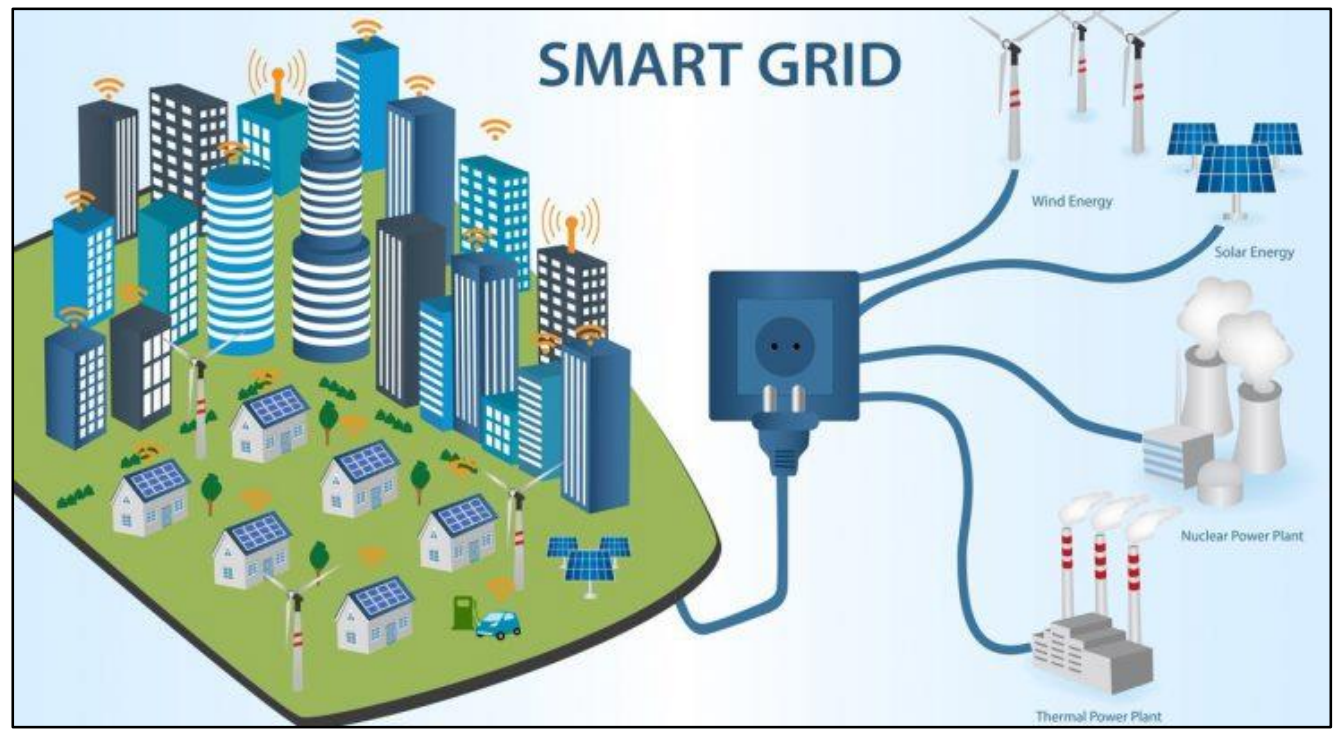

Figure 2. Smart energy grid emerging system

There are many successful examples of smart grid networks, Telegestore is founded in 2005 in Italy and considered the case study used in this review [6]. Telegestore project is the first grid used smart meters to connect 27 Million customers. Also, it is claimed to be the world's first smart grid caters to the residential scale. This smart power system offers a tremendous savings in energy. Smart powr grid is combined of three important elements, communication, information technology, and electric power. These elements operate in certain maner to enable feedback communication between the utility and consumer. The electrical transmission of energy implemented both from the electricity provider to consumer and vice versa [7-9]. When the consumers have PV systems generates electrical energy higher than the customer needs, the consumer sells the surplus energy to the utility company with incentive prices [10]. Sustainable development requires affordable access to the energy resources which is necessary to fulfil the basic needs and serve productive operations without affecting the chances of future generations. The conventional energy resources drive world economy yet fossil fuel combustion emits $56.6 \%$ of the greenhouse gases. Thus, concerns over the greenhouse gases emissions, that causes climate change pushes the efforts to integrate the renewable energy resources (wind and PV) into the power grids. However, the generated energy is random since it depends on wind or solar radiation. Therefore, such systems are intermittent as its outputs exhibit high fluctuations. Moreover, it is non-dispatchable since its output can not be manipulated to adapt any external command. In contrast, traditional grids have variability but variability in renewable energy generation is a challenge in power system operations especially when the penetration of renewable generations is high [11-13].

\section{LITERATURE REVIEW}

It is revolutionary electric grid have a fast pace of research and development. USA has intensive work on the smart grid. The smart grid can be built by the coordination of the Department of Energy (DOE) and the Electric Power Research Institute (EPRI) with national project titled "Intelligent grid [14]. This project works integrates the power grid with computation systems to enhance the reliability of power systems. Also, DOE affiliates with industrial parties through the "grid wise" program. The aim of this project is to regulate the communication and power system standards. The developed grids also require analysis and simulation instruments, trial infrastructure, smart engineering sound security and market framework. 
European Technology Platform (ETP) embrace the notion the power grids in Europe have to be economical, very flexible to meet consumer's needs, easily accessible, and reliable $[15,16]$. Also, cost efficient way of producing solutions to upgrade the conventional must be used to achieve the requirements. Therefore, technical standards and regulations to integrate power system and IT-based systems ensuring successful upgrading of old system to new smart arrangement. The international institutions define the smart power grid differently, but they agree on its framework. National Institute of Standards and Technology (NIST) consider the smart grid as a delineated power systems network use two-way feeding using information technology such as cyber communications security, intelligence and computing. To enhance the power quality and reliability, optimizing facilities to avert peak load challenges, and assuring power plants efficiency and capacity of power networks, the network must be resilient by disruption predictive maintenance and self-healing responding to disturbances occur due to the high penetration of renewable generators, Figure 3 explains the construction of any smart grid [17-20].

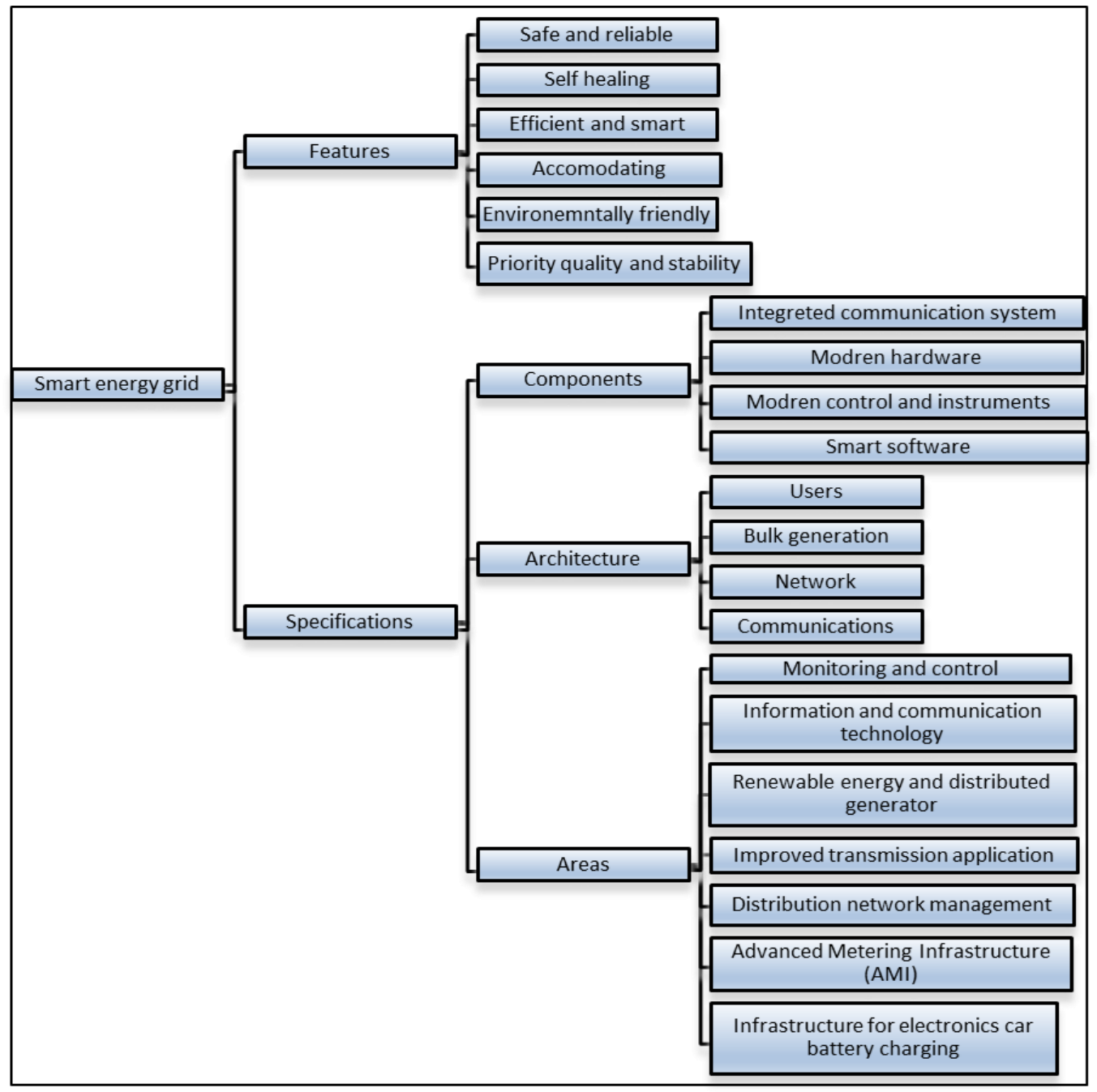

Figure 3. Smart grid implementation and implications

\subsection{Motives of smart grids}

Nowadays, the earth encountering a rising ecological pollution caused by mainly high $\mathrm{CO}_{2}$ level and other greenhouse gases emissions due to the excessive fossil fuels combustion. It is a serious cause of climate change that nations are struggling to reduce [21]. The forest fires in Australia and USA due to the high temperature of the global warming. Other issues such as sea level rising, floods, polar areas melting and unstable climates. From the energy sector that contribute most to global warming is the power generation sector. Thus, developed countries endeavor to mitigate these effects by conducting fast pace research projects to improve the performance of the renewable energy generation as environment friendly 
alternative source of energy [22]. Current renewable generators (PV, thermal and wind) trends are increasing due to the advances of smart power grid concept.

\subsection{Construction}

Smart grid networks intelligently integrate electric utilities with smart communications systems that make distribution systems more active [23]. The communication and protection systems used in smart grids are IT-based is susceptible to cyber wars and hacking attacks and vulnerable to any natural disturbance. Thus, complicated encryption systems are used to face the harming interferences and cyber-attacks. The weather detectors also can provide weather reports in real time to sense the natural disruptions early. Security schemes are also used to provide auto maintenance hence shortening repair time power shortage in power grids [24].

\subsection{Self-healing feature}

This term describes the capability of the grid to predict and quickly response to the technical disturbances occur in the system depending on the data acquisition by grid sensors and information transmitted by the communication system [25]. Thus, disturbance to distribution transformer can be detected and coded command is sent to the protection tools to automatically isolate the fault. The auto command can save the network from further damage without waiting the operator interference preventing the blackouts in surrounding areas [26].

\subsection{Smart \& efficient}

Each sector of the smart grid includes all parts of the conventional power grid such as generators, transmission, distribution and consumer. Thus, it required to be equipped with so called advanced sensor infrastructures (ASI) to provide technical parameter information in smart grid [27]. Table 1 show the comparison of the Smart system with the conventional system. The current research works on smart grids are aimed to increase the flexibility to integrate the working conventional power generation with distributed renewable generators in the forms of micro-grids and Smart grids to accommodate small scattered generators and customers. More efficient smart grid able to integrate mega renewable generators can be more useful in terms of environment improving. Whereas, current smart grid designs are focused in preserving power quality $[28,29]$. Therefore, technical issues harm the consumers and utilities of electric energy is reduced to the minimum. Unstable voltage, fluctuating frequency and harmonics are the most common problems in the smart grids. Therefore, several devices such as collector, recording data, automation, sensors, smart meters, real time data display, data management, and two-way communication applications are added to the power grid [30].

Table 1. The general comparison between the current power system and the smart energy grid

\begin{tabular}{|c|c|c|}
\hline No & Conventional power systems & Smart energy grid \\
\hline 1. & Centralized generation. & $\begin{array}{l}\text { Distributed renewable generation with plug and play } \\
\text { feature }\end{array}$ \\
\hline 2. & One-way communication & $\begin{array}{l}\text { Two-way communication of energy resources } \\
\text { interconnection }\end{array}$ \\
\hline 3. & Electromechanical system & Self-monitoring by many sensors and monitors \\
\hline 4. & Small number of sensors & Self-healing. Ability to detect and respond to faults \\
\hline 5. & Failures and blackouts need manual restoration. & $\begin{array}{l}\text { Adaptive for islanding, using pervasive and extensive } \\
\text { control [31] }\end{array}$ \\
\hline 6. & Manual monitoring Limited control & Greatly expanded control using data acquisition \\
\hline 7. & Cannot be integrated with PV systems & Can integrated with all sorts of renewable generators \\
\hline 8. & Vulnerable toward cyber attacts, vandalism, and natural effects & $\begin{array}{l}\text { Resilient toward attacks, natural effects, and vandalism } \\
\text { with rapid restoration capabilities [32] }\end{array}$ \\
\hline
\end{tabular}

However, the network becomes very complex in terms of communication and coordination among the sensors. EPRI designed a new network includes AMI, active control, and data management. Other aspects such as internet network, energy storage, hybrid cars, portals consumers and distributed generators are used to create smart management at the consumer end [33]. The intelligent infrastructure installed in the power grid as shown in Figure 4, to assure the maximum accessibility in a broad range. The integrated data sensors and communication technologies between consumers and the power grid enhance the resilience of the network. As a result, raw information from the sensors is sent by fiber optic cables or wireless networks to be processed for further controlling steps [34]. There are some supporting elements such as SCADA are used to analyze, diagnose, and predict the pattern of power flow incautiously. They work in dynamic, fast, and real time to assure the stability of the grid. 


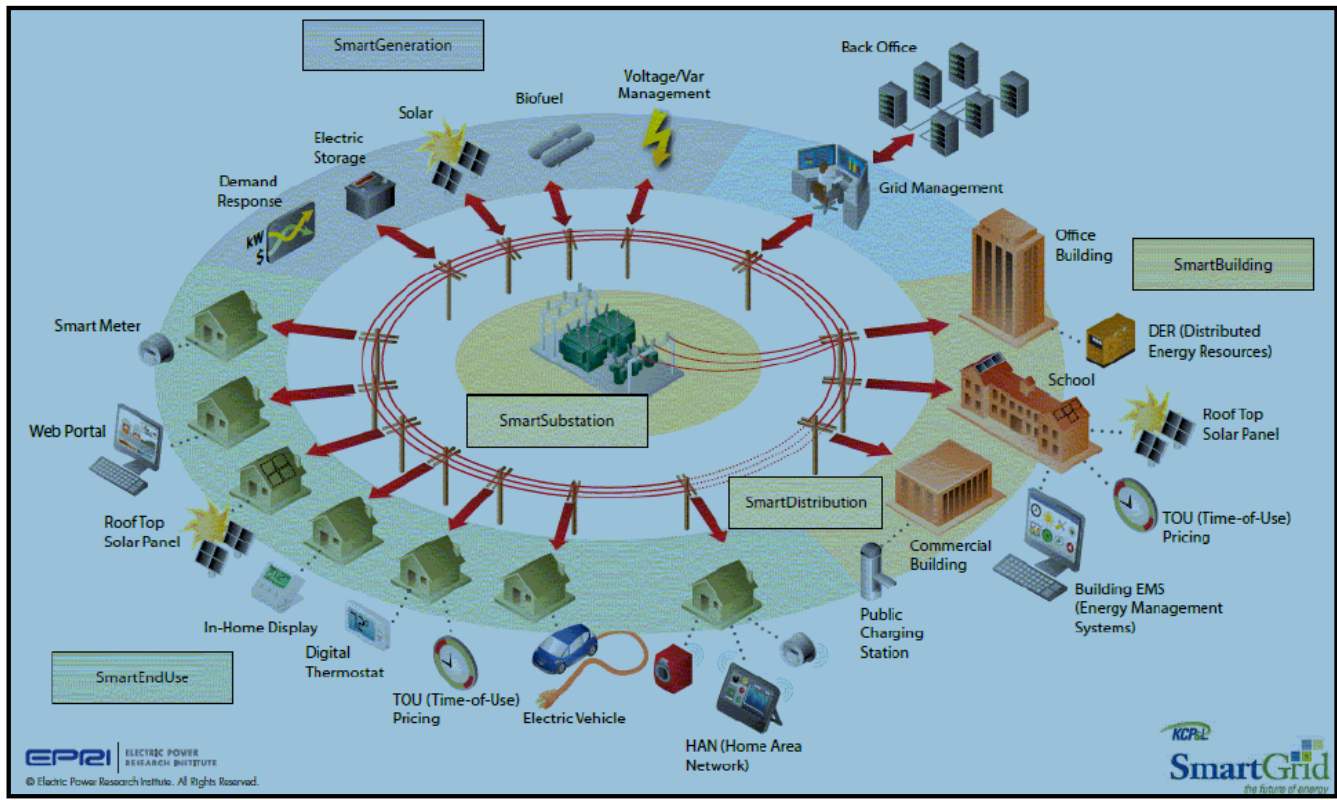

Figure 4. Smart grid model and scenario by EPRI [35]

\subsection{Interface and auxiliary systems}

Smart interface between the used and the grid permits the distributed generators to ride through any disturbance to restore the voltage stability in the whole grid. The distributed generation is expected to play role to stabilize the power grid. A smart home is also equipped feedback systems to increase the efficiency of the voltage restoration and harmonics elimination [36]. Thus, distribution generation includes more power electronic devices to minimize harmonics, fluctuating generation failures. Energy management system (EMS) is automated control core of the power grids. users require simple control architecture for easy integration to avoid blockage. In an area where power outages are normal constraints, outage management system (OMS) can be the main part of DMS. Location is another important factor of failures and interface with geographic information systems (GIS) is vital in smart grid. Also, advanced metering infrastructure (AMI) is providing dynamic rates, power quality monitoring, and remote measurement, load restraint. More advanced topologies integrate distribution automation [37-40].

\section{SMART GRID POLICY AND CURRENT WORKS}

The advanced operation systems in smart grids is designed to avoid blackouts and facilitate the integration of renewable generators with the distribution systems. The smart grid is illustrated in Figure 5 illustrate the integration of communication and information technology [41]. The demand of the high-power quality, reliable energy supply and the rapid increase of global energy consumption motivate scientists to discover new energy related technologies. Policy and decision makers have been promoting the use of the renewable energy, especially the wind and the photovoltaic, which may be connected to the distribution systems. Technical standards were established to create the procedures to interconnect the distribution energy resources (DER) to the distribution grid. For example, IEEE 1547 which basically required the DER not to cause any overvoltage or protection coordination challenge to the grid [42].

The continuous advancement in DER has led to lower cost and high penetration at larger size. However, it has an adverse impact on transmission systems and voltage stability. The North American Electric Reliability Corporation "NERC" provided a guidance to revise the standard PRC-024 to accommodate the DER limits. The latest version of PRC-024-2 is mandated in July of 2016. A revision of IEEE 1547-a was published in 2014 as a draft guidance to change the voltage-time and the frequency-time setting of the inverter and to allow the voltage and the frequency ride through the fault and to give the utility the option to allow the inverter to regulate the distribution voltage. [43- 45]. Nowadays, the research works in improving the reliability of the system with to distributed energy resources, such that:

a. It provides an active power reduction in case of over-frequency.

b. It has the capability of the fault ride through (FRT).

c. It provides the grid reactive power and voltage support.

d. It allows higher DER penetration level 
The above functions improve the grid resiliency and reliability due to robust voltage stability and self-healing from voltage and frequency fluctuation and faults. Economically, in the long term the grid can work without many current devices that are used to regulate the grid voltage [46].

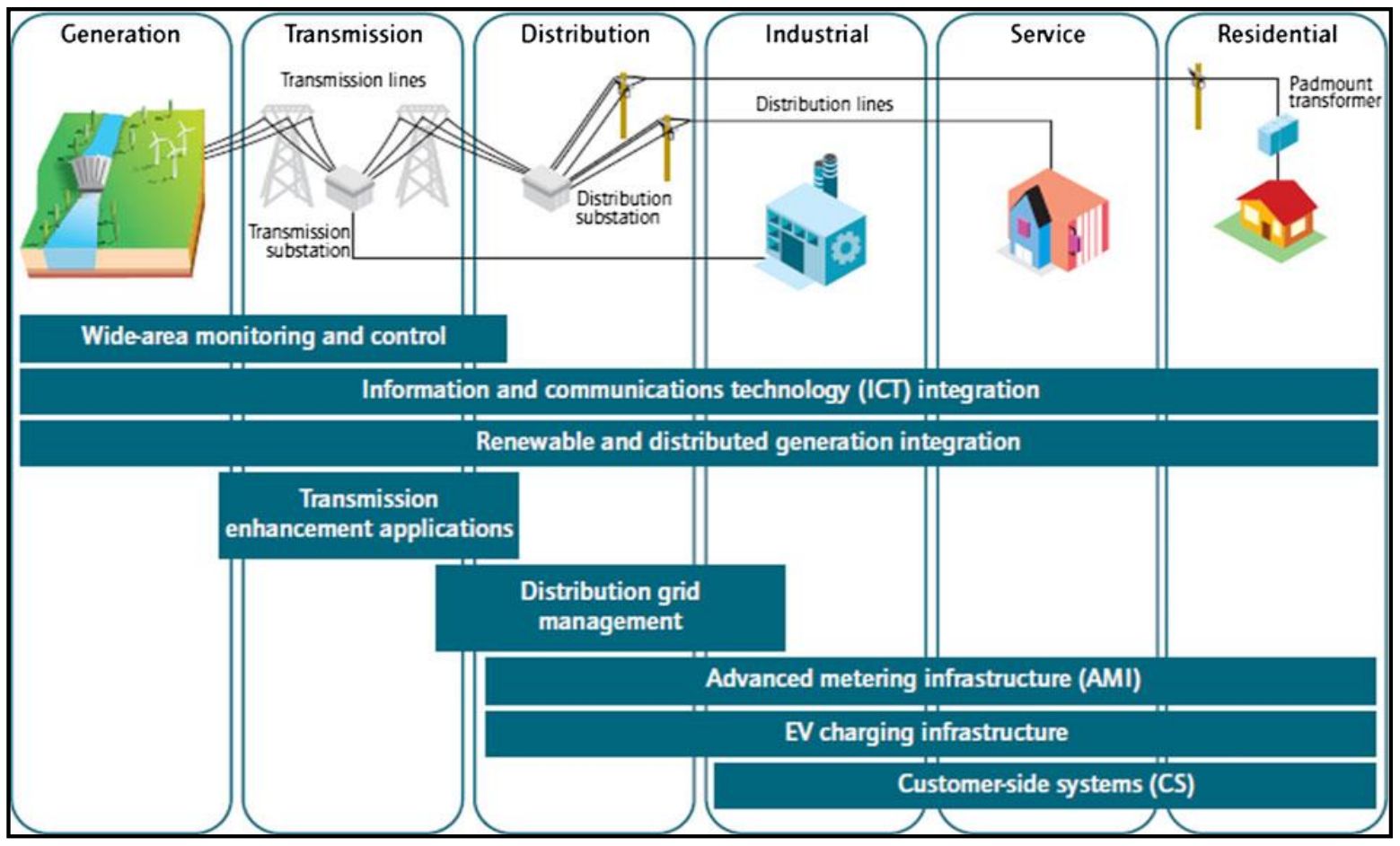

Figure 5. The technologies combine the smart grid structure [47]

Also, many works done on the smart meters, the meters should send the data that received by AMI and send it to the data meter management system (MDMS) [48]. MDMS manages the data and analysis to provide information for the utilities. AMI allows communication between utilities and meters to provide the consumers with following functions: The price of a remote customer and usage time, Ability to collect, store, and report customer energy consumption for any required period, Enhance the energy diagnosis using detailed generated load profile, Identifying the location of a remote powered area using a metering function that sends a signal when the meter is out and when the power is restored [49], Remote linking and disconnection, Ability to detect the losses and theft activities, retailing energy service providers to manage revenue using more effective management [50].

\section{CONCLUSION}

The smart energy grid is novel electric power system represent a drastic evolution of the traditional electric grid such that energy flow is no longer unidirectional as well as the distribution system. farturemore, the customer side can play very curtail role to stabilize the grid. The supply and demand sides play vital role to keep the system resilient. The advantages, components, previous, and future advances of the smart grid is presented in this review work to shed the light on this hot topic in the hulls of electrical research institution. Several advantages of smart grids have been discussed such as: safety and reliability, self-healing, efficiency, Intelligence, accommodating, environment friendly, quality and stability features. The specifications have been invistigated from many aspacts such as: architecture, components, and areas. The covered areas are integration with renewable distributed generators, control and monitoring, integration with information and communication technologies, and distribution management. The smart grid enables consumers to contribute on the stability restoration and control their energy consumption. 


\section{REFERENCES}

[1] Richard J. Campbell, "The Smart Grid: Status and Outlook," Congressional Research Service, 2018, [Online], Available at: www.crs.gov.

[2] K. Kopsidas and M. Abogaleela, "Utilizing Demand Response to Improve Network Reliability and Ageing Resilience," in IEEE Transactions on Power Systems, vol. 34, no. 3, pp. 2216-2227, May 2019.

[3] Y. Liu, S. Lei and Y. Hou, "Restoration of Power Distribution Systems With Multiple Data Centers as Critical Loads," in IEEE Transactions on Smart Grid, vol. 10, no. 5, pp. 5294-5307, Sept. 2019.

[4] M. Song, C. Gao, M. Shahidehpour, Z. Li, J. Yang and H. Yan, "State Space Modeling and Control of Aggregated TCLs for Regulation Services in Power Grids," in IEEE Transactions on Smart Grid, vol. 10, no. 4, pp. 4095-4106, July 2019.

[5] IEEE innovation at work, "The Smart Grid and Renewable Energy", [Online], Available at: https://innovationatwork.ieee.org/smart-grid-transforming-renewable-energy/.

[6] M. Qasim Taha and M. A. Lpizra, "Design a new PWM switching technique in multilevel converters," 2016 Annual Connecticut Conference on Industrial Electronics, Technology \& Automation (CT-IETA), Bridgeport, CT, pp. 1-4, 2016.

[7] Jamshid Aghaei, Mohammad-Iman Alizadeh, "Demand response in smart electricity grids equipped with renewable Energy sources: A review," Renewable and Sustainable Energy Reviews, vol. 18, pp. 64-72, February 2013.

[8] Paul Haase, "Intelligrid: A smart network of power," EPRI journal, pp. 28-32, 2005.

[9] Francisco-Javier Ferrández-Pastor,Higinio Mora,Antonio Jimeno-Morenilla,Bruno Volckaert, "Deployment of IoT Edge and Fog Computing Technologies to Develop Smart Building Services," Sustainability, vol. 10, no. 11, 2018.

[10] Moamin A. Mahmoud, Alicia Y. C. Tang, Andino Maseleno, Fung-Cheng Lim, Hairoladenan Kasim, Christine Yong, "Chapter 63 Towards the Development of a Smart Energy Grid," Springer Science and Business Media LLC, 2020.

[11] Z. Bie, Y. Lin, G. Li and F. Li, "Battling the Extreme: A Study on the Power System Resilience," in Proceedings of the IEEE, vol. 105, no. 7, pp. 1253-1266, July 2017.

[12] M. Panteli and P. Mancarella, "Influence of extreme weather and climate change on the resilience of power systems: Impacts and possible mitigation strategies," Electric Power Systems Research, vol. 127, pp. 259-270, October 2015.

[13] Mohammed Qasim Taha, Zaid Husain, Ahmed Khalid Ahmed, "Two-level scheduling scheme for integrated 4GWLAN network," International Journal of Electrical and Computer Engineering (IJECE), vol. 10, no. 3, pp. 2633-2643, June 2020.

[14] A. Golshani, W. Sun, Q. Zhou, Q. P. Zheng and Y. Hou, "Incorporating Wind Energy in Power System Restoration Planning," in IEEE Transactions on Smart Grid, vol. 10, no. 1, pp. 16-28, Jan. 2019.

[15] X. Liu, M. Shahidehpour, Z. Li, X. Liu, Y. Cao and Z. Bie, "Microgrids for Enhancing the Power Grid Resilience in Extreme Conditions," in IEEE Transactions on Smart Grid, vol. 8, no. 2, pp. 589-597, March 2017.

[16] A. Golshani, W. Sun, Q. Zhou, Q. P. Zheng, J. Wang and F. Qiu, "Coordination of Wind Farm and PumpedStorage Hydro for a Self-Healing Power Grid," in IEEE Transactions on Sustainable Energy, vol. 9, no. 4, pp. 1910-1920, Oct. 2018.

[17] Jose Evora, Jose Juan Hernandez, Mario Hernandez, "A MOPSO method for direct load control in smart grid," Expert Systems with Applications, vol. 42, no. 21, pp. 7456-7465, 30 November 2015.

[18] R. R. Nejad and W. Sun, "Chance-constrained Service Restoration for Distribution Networks with Renewables," 2018 IEEE International Conference on Probabilistic Methods Applied to Power Systems (PMAPS), Boise, ID, pp. 1-6, 2018.

[19] C. Ahn and H. Peng, "Decentralized and real-time power dispatch control for an islanded microgrid supported by distributed power sources," Energies, vol. 6, no. 12, pp.6439-6454, 2013.

[20] N Dahal, O Abuomar, R King, V Madan, "Event stream processing for improved situational awareness in the smart grid," Expert Systems with Applications, vol. 42, no. 20, pp. 6853-6863, 15 November 2015.

[21] Jiang Tao, Yang Jun, Xun Hua, "Research and application of intelligent alarm system for power equipment status," Inner Mongolia Electric Power, vol. 35, no. 6, pp. 45-49, 2017.

[22] Amer Tayes Saeed, Mohamed Qasim Taha, Abdullah Khalid Ahmed, "Tracking technique for the sudden change of PV inverter load," International Journal of Power Electronics and Drive System (IJPEDS), vol. 10, no. 4, pp. 2076-2083, December 2019.

[23] Guo Chuang-Xin, Zhu Cheng-Zhi, Zhang Lin, Peng Ming-Wei, Liu Yi, "A fault diagnosis method for power transformer based on multiclass multiple-kernel learning support vector machine," Proceedings of the CSEE, vol. 30, no. 13, pp. 128-134, 2010.

[24] Q. Mao and N. Li, "Assessment of the impact of interdependencies on the resilience of networked critical infrastructure systems," Natural Hazards, vol. 93, no. 1, pp. 315-337, 2018.

[25] J. V. Milanović and W. Zhu, "Modeling of Interconnected Critical Infrastructure Systems Using Complex Network Theory," in IEEE Transactions on Smart Grid, vol. 9, no. 5, pp. 4637-4648, Sept. 2018.

[26] Y. Almoghathawi, K. Barker, and L. A. Albert, "Resilience-driven restoration model for interdependent infrastructure networks," Reliability Engineering \& System Safety, vol. 185, pp. 12-23, May 2019.

[27] Y. Tan, A. K. Das, P. Arabshahi and D. S. Kirschen, "Distribution Systems Hardening Against Natural Disasters," in IEEE Transactions on Power Systems, vol. 33, no. 6, pp. 6849-6860, Nov. 2018.

[28] J. Lin, W. Yu, N. Zhang, X. Yang, H. Zhang and W. Zhao, "A Survey on Internet of Things: Architecture, Enabling Technologies, Security and Privacy, and Applications," in IEEE Internet of Things Journal, vol. 4, no. 5, pp. 1125-1142, Oct. 2017. 
[29] Battaglini, A., J. Lilliestam, A. Haas and A. Patt, "Development of super smart grids for a more efficient utilisation of electricity from renewable sources," Journal of Cleaner Production, vol. 17, no. 10, pp. 911-918, July 2009.

[30] Younes S. Alwan, Mohammad Sami Zidan, Mohammed Qasim Taha, "Evaluation of mobile microwave electric field severity at Al-door residential complex in Iraq," Indonesian Journal of Electrical Engineering and Computer Science (IJEECS), vol. 14, no. 3, pp. 1281-1285, June 2019.

[31] S. Deilami, A. S. Masoum, P. S. Moses and M. A. S. Masoum, "Real-Time Coordination of Plug-In Electric Vehicle Charging in Smart Grids to Minimize Power Losses and Improve Voltage Profile," in IEEE Transactions on Smart Grid, vol. 2, no. 3, pp. 456-467, Sept. 2011.

[32] Dibangoye, J., A. Doniec, H. Fakham, F. Colas and X. Guillaud, "Distributed economic dispatch of embedded generation in smart grids," Engineering Applications of Artificial Intelligence, vol. 44, pp. 64-78, September 2015.

[33] Pertti Järventausta, Sami Repo, Antti Rautiainen, Jarmo Partanen, "Smart grid power system control in distributed generation environment," Annual Reviews in Control, vol. 34, no. 2. pp. 277-286, 2010.

[34] N. T. Bazargani and S. M. T. Bathaee, "A novel approach for probabilistic hurricane resiliency assessment of an active distribution system using point estimate method," 2018 19th IEEE Mediterranean Electrotechnical Conference (MELECON), Marrakech, pp. 275-280, 2018.

[35] Zhang Jisheng, Zhang Bo, Yu Ye, "Intelligent evaluation of substation equipment operation quality based on big data structure," Power Systems and Big Data, vol. 20, no. 9, pp. 37-41, 2017.

[36] Abdullah Khalid Ahmed, Mohammed Qasim Taha, Ahmed Shamil Mustafa, "On-road Automobile License Plate Recognition Using Co-Occurrence Matrix", Journal of Advanced Research in Dynamical \& Control Systems, vol. 10, no. 7, 2018.

[37] Song Renjie, Wang Xiaodong, "Research on assessment and analysis system of condition-based maintenance for power transmission and transformation equipment," Power System Protection and Control, vol. 36, no. 9, pp. 54-57, 2008.

[38] Yang Jiahua, Yang Zhenrui, Lu Jun, Jiang Chen, "Risk assessment research on power transformers based on risk probability for power transformer," Power System and Clean Energy, vol. 28, no. 3, pp. 44-49, 2012.

[39] Li Xuelong, Gong Haigang, "A survey on big data," Science China Information Sciences, vol. 45, no. 1, pp. 1-44, 2015.

[40] Flavia Gangale, Anna Mengolini, Ijeoma Onyeji, "Consumer engagement: An insight from smart grid projects in Europe," Energy Policy, vol. 60, pp. 621-628, 2013.

[41] V. C. Gungor, B. Lu and G. P. Hancke, "Opportunities and Challenges of Wireless Sensor Networks in Smart Grid," in IEEE Transactions on Industrial Electronics, vol. 57, no. 10, pp. 3557-3564, Oct. 2010.

[42] Mustafa Hamid Al-Jumaili, Ahmed Subhi Abdalkafor, Mohammed Qasim Taha, "Analysis of the hard and soft shading impact on photovoltaic module performance using solar module tester," International Journal of Power Electronics and Drive System (IJPEDS), vol. 10, no. 2, pp. 1014-1021, June 2019.

[43] Daniel Grzonkaa, Joanna Kołodzieja, Jie Taob, Samee Ullah Khan, "Artificial neural network support to monitoring of the evolutionary driven security aware scheduling in computational distributed environments," Future Generation Computer Systems, vol. 51, pp. 72-86, October 2015.

[44] V. C. Gungor et al., "Smart Grid Technologies: Communication Technologies and Standards," in IEEE Transactions on Industrial Informatics, vol. 7, no. 4, pp. 529-539, Nov. 2011.

[45] Wu Junying, Liu Mingsuo, Chang Yongjuan, et al, "Application and research of transformer equipment status and risk analysis based on big data," Power Systems and Big Data, 2017.

[46] Zhang Dongxia, Miao Xin, Liu Liping, et al, "Research on development strategy for smart grid big data," Zhongguo Dianji Gongcheng Xuebao/Proceedings of the Chinese Society of Electrical Engineering, vol. 35, no. 1, pp. 2-12, January 2015.

[47] Moath Jarrah,Manar Jaradat, Yaser Jararweh, Mahmoud Al-Ayyoub, Abdelkader Bousselham, "A hierarchical optimization model for energy data flow in smart grid power systems," Information Systems, vol. 53, pp. 190-200, October-November 2015.

[48] Mohammed Qasim Taha, Mustafa Hamid AL-Jumaili, Abdullah Khalid Ahmed, "Modeling the Dielectric Mediums Impact on Coaxial Transmission Line Performance," Journal of Engineering and Applied Sciences, vol. 13, no. 20, pp: 8419-8425, 2018.

[49] Peng Xiaosheng, Deng Diyuan, Cheng Shijie, et al., "Key technologies of electric power big data and its application prospects in Smart Grid," Zhongguo Dianji Gongcheng Xuebao/Proceedings of the Chinese Society of Electrical Engineering, vol. 35, no. 3, pp. 503-511, February 2015.

[50] Liu Keyan, Sheng Wanxing, Zhang Dongxia, et al. "Big data application requirements and scenario analysis in smart distribution network," Zhongguo Dianji Gongcheng Xuebao/Proceedings of the Chinese Society of Electrical Engineering, vol. 35, no. 2, pp. 287-293, January 2015. 